RESEARCH NOTE

\title{
Resistência ao Jejum de Triatoma nitida Usinger, 1939 em Laboratório (Hemiptera, Reduviidae, Triatominae)
}

\section{Cleber Galvão /+ , José Jurberg , Herman Lent*}

\begin{abstract}
Laboratório Nacional e Internacional de Referência em Taxonomia de Triatomíneos, Departamento de Entomologia, Instituto Oswaldo Cruz, Av. Brasil 4365, 21045-900 Rio de Janeiro, RJ, Brasil *Centro de Ciências Biológicas, Universidade Santa Úrsula, Rua Jornalista Orlando Dantas 59, 22231-010 Rio de Janeiro, RJ, Brasil
\end{abstract}

Resistance to fast of Triatoma nitida Usinger,1939 in laboratory - The authors observed the resistance to the fast of Triatoma nitida in all phases of the life cycle. The nymphs of 1 st and 2 nd instars resisted about two months, and the $3 r d$ ones more than three months and the 4th were more resistants (five months). The nymphs of 5th instar resisted for four months, and the adults about two months.

Key words: Triatominae - Triatoma nitida - Chaga's disease - resistance to starvation

Triatoma nitida foi descrita por Usinger em 1939, com base em espécimes coletados na Guatemala e Honduras; somente cerca de uma década depois sua infecção natural pelo Trypanosoma cruzi foi relatada por E Dias (1952 Rev Bras Malariol D trop 4: 75-84). JR Leon (1959 Rev Goiana Med 5: 445-455) chamou a atenção para o alto grau de infecção dessa espécie na Guatemala, onde $83 \%$ dos espécimes capturados albergavam o T. cruzi, colocando-a ao lado de Rhodnius prolixus Stal,1859 e de Triatoma dimidiata (Latreille,1811) como as únicas transmissoras da doença de Chagas naquele país; anos mais tarde W González-Angulo e RE Ryckman (1967 J Med

Com auxílio do CNPq, FAPERJ, convênio BIRD/FNS/ FIOCRUZ n ${ }^{0} 027 / 93$ e Comission of the European Communities STD-TS3-CT920092

+Autor de contato. Fax: 55-21-290.9339

Recebido em 21 de novembro de 1995

Aceito em 29 de maio de 1996
Ent 4: 44-47) encontraram, pela primeira vez, representantes dessa espécie no México (Yucatan).

Segundo R Zeledón (1983 Interciência 8: 384394) T. nitida é uma espécie silvestre difícil de ser encontrada, pois, apesar de os adultos invadirem o domicílio ocasionalmente, não são capazes de colonizar.

Até o presente, apenas trabalhos sobre sistemática e morfologia dedicados a esta espécie foram publicados estando sob este ponto bem estudada; entretanto, pouco se conhece sobre seus hospedeiros e habitats naturais. Alguns aspectos de sua biologia foram abordados recentemente por C Galvão et al. (1995 Mem Inst Oswaldo Cruz 90: 657-663) onde os autores destacaram o longo período de desenvolvimento em laboratório e o pequeno número de defecações realizadas imediatamente após o repasto.

O presente trabalho teve como objetivo estabelecer o período de resistência ao jejum em condições controladas no laboratório.

Os insetos estudados são provenientes do insetário do Laboratório Nacional e Internacional de Referência em Taxonomia de Triatomíneos, Departamento de Entomologia, Instituto Oswaldo Cruz, onde são mantidos em temperatura ambiente com alimentação quinzenal em pombos (Columba livia).

Machos e fêmeas foram transferidos da colônia para um recipiente metálico de $21 \mathrm{~cm}$ de altura e $16 \mathrm{~cm}$ de diâmetro com o fundo de tela de arame visando facilitar a coleta dos ovos que deram origem a uma nova colônia que foi mantida em câmara climatizada tipo B.O.D. a temperatura de $28+/-1{ }^{\circ} \mathrm{C}$ e $80+/-5 \%$ de UR, com fotofase de 12 $\mathrm{h}$ e alimentação semanal em camundongos albinos (Mus musculus). Desta colônia foram retirados 50 ovos e 50 ninfas visivelmente não alimentadas de cada estádio (exceto do $5^{\circ}$ estádio de onde foram retirados 60 espécimes). Os insetos foram agrupados, de acordo com a fase de desenvolvimento, em cristalizadores de vidro de $20 \mathrm{~cm}$ de altura por $17 \mathrm{~cm}$ de diâmetro e submetidos ao jejum por 15 dias. Ao final desse período oferecia-se a fonte alimentar por cerca de $5 \mathrm{~h}$.

Após a eclosão, ou muda, isolaram-se 30 espécimes de cada estádio, 15 machos e 15 fêmeas, em frascos de Borrel numerados conforme a data da muda. Os insetos foram mantidos em jejum e observados diariamente até a morte.

Segundo A Neiva e H Lent (1936 Rev Ent Rio de Janeiro 6: 153-190) os primeiros relatos sobre a capacidade de resistência ao jejum se devem a Darwin, que observou um espécime resistir à falta de alimento por quatro meses, a Laboulbène que observou um período ainda maior e a Porter que constatou a sobrevivência de um espécime de 
Triatoma infestans (Klug, 1834) durante 17 meses de jejum. Desde então, diversos autores têm documentado a capacidade de jejum desses insetos. C Uribe (1926 J Parasitol 13: 129-136) observou uma ninfa de $3^{\circ}$ estádio de $R$. prolixus resistir à privação alimentar por cinco meses enquanto PA Buxton (1930 Trans Entomol Soc London 78: 227236) afirmou que os machos são capazes de resistir por 41 dias e as fêmeas por 35 dias em média. $\mathbf{J}$ Pelegrino (1952 Rev Brasil Biol 12: 317-320) foi o primeiro a ressaltar a importância epidemiológica da capacidade de resistência ao jejum, lembrando que, em situações adversas, estes insetos podem se deslocar ativa ou passivamente, mantendo-se vivos até encontrar um novo ambiente favorável, criando, assim, novos focos da doença em áreas anteriormente livres de vetores. Segundo JCP Dias (1965 Rev Bras Malariol D trop 17: 55-63) a resistência ao jejum seria extremamente vantajosa para as espécies domiciliadas, que, protegidas em frestas inacessíveis à aspersão de inseticidas, resistiriam até que o efeito residual cessasse, quando então sairiam a procura do alimento.

Os resultados obtidos para $T$. nitida estão na Tabela. Observa-se que as ninfas de $1^{\circ}$ e $2^{\circ}$ estádios resistiram por cerca de dois meses, as do $3^{\circ}$ estádio por mais de três e as do $4^{\circ}$ foram as mais resistentes (sobreviveram por volta de cinco meses). Este período diminuiu consideravelmente nas ninfas de $5^{\circ}$ estádio, que suportaram a falta de alimento por quatro meses em média. Os adultos sobreviveram por períodos semelhantes aos do $1^{\circ}$ e $2^{\circ}$ estádios e

\section{TABELA}

Período de resistência ao jejum (em dias) em Triatoma nitida Usinger, 1939

\begin{tabular}{lcrrrrr}
\hline Fases & Min. & Max. & $\overline{\mathrm{X}}$ & \multicolumn{1}{c}{$\mathrm{S}$} & $\mathrm{S}^{2}$ & $\mathrm{~N}$ \\
\hline $1^{\circ}$ estádio & 33 & 71 & 56,3 & 9,2 & 86,1 & 30 \\
$2^{\circ}$ estádio & 16 & 113 & 63,0 & 25,1 & 632,4 & 30 \\
$3^{\circ}$ estádio & 65 & 167 & 102,5 & 26,9 & 724,9 & 30 \\
$4^{\circ}$ estádio & 82 & 221 & 158,0 & 25,4 & 648,7 & 30 \\
$5^{\circ}$ estádio & 41 & 159 & 114,3 & 26,4 & 702,2 & 30 \\
Machos & 12 & 85 & 58,6 & 19,9 & 398,8 & 15 \\
Fêmeas & 39 & 89 & 66,0 & 16,0 & 256,6 & 15 \\
\hline
\end{tabular}

Min. = período mínimo. Máx. = período máximo. $\overline{\mathrm{X}}=$ média. $\mathrm{S}=$ desvio padrão. $\mathrm{S}^{2}=$ variância. $\mathrm{N}=$ tamanho da amostra. as fêmeas mostraram-se um pouco mais resistentes que os machos.

As comparações entre os resultados obtidos por diversos autores devem ser feitas levando-se em consideração as diferentes metodologias e condições de realização dos experimentos. JM Costa e J Jurberg (1989 Mem Inst Oswaldo Cruz 84: 129-137) apresentaram tabelas comparativas de vários trabalhos; nota-se que ocorreram variações no período de resistência de acordo com a metodologia utilizada. J Jurberg e JM Costa (1989 Mem Inst Oswaldo Cruz 84: 393-399) chamaram a atenção para os períodos divergentes encontrados por vários autores para a mesma espécie. Os períodos de resistência obtidos por A PerlowagoraSzumlewicz (1969 Rev Brasil Malariol D trop 21: 117-159) para $T$. infestans foram inferiores aos registrados por Pelegrino (1952 loc.cit.), WH Hack (1955 Ann Inst med Reg 4: 125-147) e E Dias (1956 Mem Inst Oswaldo Cruz 54: 115-124) que estudaram a mesma espécie.

No presente trabalho, os resultados concordam, em linhas gerais, com os obtidos, por outros autores, em condições de laboratório semelhantes, mas demonstram que $T$. nitida possui uma grande capacidade de resistência, superior a de outras espécies do gênero.

MJ Costa e ALP Perondini (1973 Rev Saúde Públ S Paulo 7: 207-217) mantiveram o T. brasiliensis em jejum a $30^{\circ} \mathrm{C}$ e 70 a $80 \%$ de U.R., e obtiveram médias inferiores às de $T$. nitida em todas as fases do ciclo de vida; o mesmo ocorreu em relação ao $T$. sordida mantido a $30^{\circ} \mathrm{C}$ por $\mathrm{E}$ Juarez e EPC Silva (1982 Rev Saúde Públ S Paulo 16: 1-36). A resistência ao jejum de $T$. nitida foi parcialmente superior (maior no $1^{\circ}$ e $5^{\circ}$ estádios) à do $R$. prolixus estudado por MD Feliciangeli et al. (1980 Rev Inst Med Trop S Paulo 22: 53-61) e, totalmente superior à de cinco espécies mantidas a $30{ }^{\circ} \mathrm{C}$ : $R$. nasutus, $R$. neglectus, $P$. megistus, $T$. vitticeps e T. rubrovaria (IG Silva 1985 Tese de Doutorado, UFPR, Brasil).

Agradecimentos: ao Dr. Rodrigo Zeledón, da Universidade da Costa Rica pelos espécimes que originaram a colônia de T. nitida; à técnica Vanda Cunha pela observação diária; ao técnico José Luís da Costa Giesteira e à estagiária Luciana da Fonseca Silva pela manutenção do insetário. 